\title{
Microstructural Comparison of Lead-Free Solder (Bi5-Ag3-Cu0.5-Sn) Prepared by Mechanical Alloying and Casting Route.
}

\author{
C. Carreño-Gallardo, I. Estrada-Guel, and R. Martínez-Sánchez.
}

Centro de Investigación en Materiales Avanzados (CIMAV), Miguel de Cervantes No.120, C.P. 31109, Chihuahua, Chih., México.

The electronic and electrical industries are facing an increasing pressure from environmental legislation in many countries to remove lead from their products. This is because of the hazards to health during manufacture of the components, and ecological damage caused by materials containing $\mathrm{Pb}$. Lead-free solder are intended to be a substitute for traditional $\mathrm{Sn}-\mathrm{Pb}$ eutectic system in conventional processes in the near future. Among them, Sn-Ag eutectic solder is an attractive candidate for meeting the requirements for high-temperature demanding service environments, such as automotive applications. However, Sn-Ag system presents high melting point and lower wettability compared to $\mathrm{Sn}-\mathrm{Pb}$. To improve the physical properties and decrease the melting temperature, some elements, such as $\mathrm{Bi}$ and $\mathrm{Cu}$, are added to $\mathrm{Sn}-\mathrm{Ag}$. As a matter of fact, $\mathrm{Bi}-\mathrm{Ag}-\mathrm{Cu}-$ Sn system is regarded as one with high quality, performance and can meet the requirement electronic packaging. There are a great diversity of routes for the elaboration of this type of new alloys, mechanical alloying (MA) is one of them.

Two methods were employed to obtain this lead-free solder: MA and conventional casting route. As raw material, was used a mixture of high purity crystalline elemental metallic powders (purity $\geq$ 99\% and particle size $<74 \mu \mathrm{m}$ ). Nominal composition was set to Bi5-Ag3-Cu0.5-Sn. The mixture was processed in a high energy shaker mill (SPEX-8000M) in dry condition under argon atmosphere at room temperature.

The Bi5-Ag3-Cu0.5-Sn solder was studied in terms of microstructure. Fig. 1a shows a representative view of the microstructure in as-milled powder, while Fig. 1b shows the microstructure of final product in the as-cast condition. Milled products present a lamellar structure characteristic of ductile-ductile system. This lamellar structure is produced by micro-forging process. The existence of fine size $(0.5 \mu \mathrm{m})$ homogeneously dispersed $\mathrm{Ag}_{3} \mathrm{Sn}$ intermetallic compound was observed. By the other hand, sample produced by casting route presents the same intermetallic compound with different shape (plates form) and large size $\left(\begin{array}{lll}5-25 & \mathrm{~m}\end{array}\right)$. In both cases (micrograph) $\mathrm{Ag}_{3} \mathrm{Sn}$ is showed by arrows. Another important difference was the Bi distribution; in samples produced by MA, Bi was found homogeneously distributed.

Fig. $2 \mathrm{a}$ and $2 \mathrm{~b}$ present SEM-BEI micrographs from sample produced by MA and casting route respectively. In as-milled powders, high microporosity is evident (Fig. 2a); additionally, the Bi dispersion is apparently homogeneous. $\mathrm{Ag}_{3} \mathrm{Sn}$ intermetallic compound particles show very fine size, lower than $1 \mu \mathrm{m}$. Analyzing the elemental compositions of the particles by EDS, it seems that the larger particles tend to be $\mathrm{Cu}_{6} \mathrm{Sn}_{5}$ while the smaller tend to be $\mathrm{Ag}_{3} \mathrm{Sn}$. As-cast sample (Fig. 2b) presents fine grain size $(10-20 \mu \mathrm{m})$, coarse particles of $\mathrm{Ag}_{3} \mathrm{Sn}$ intermetallic compound apparently growths in the grain border and a heterogeneous distribution of $\mathrm{Bi}$ particles are present in the $\mathrm{Sn}$ matrix. 

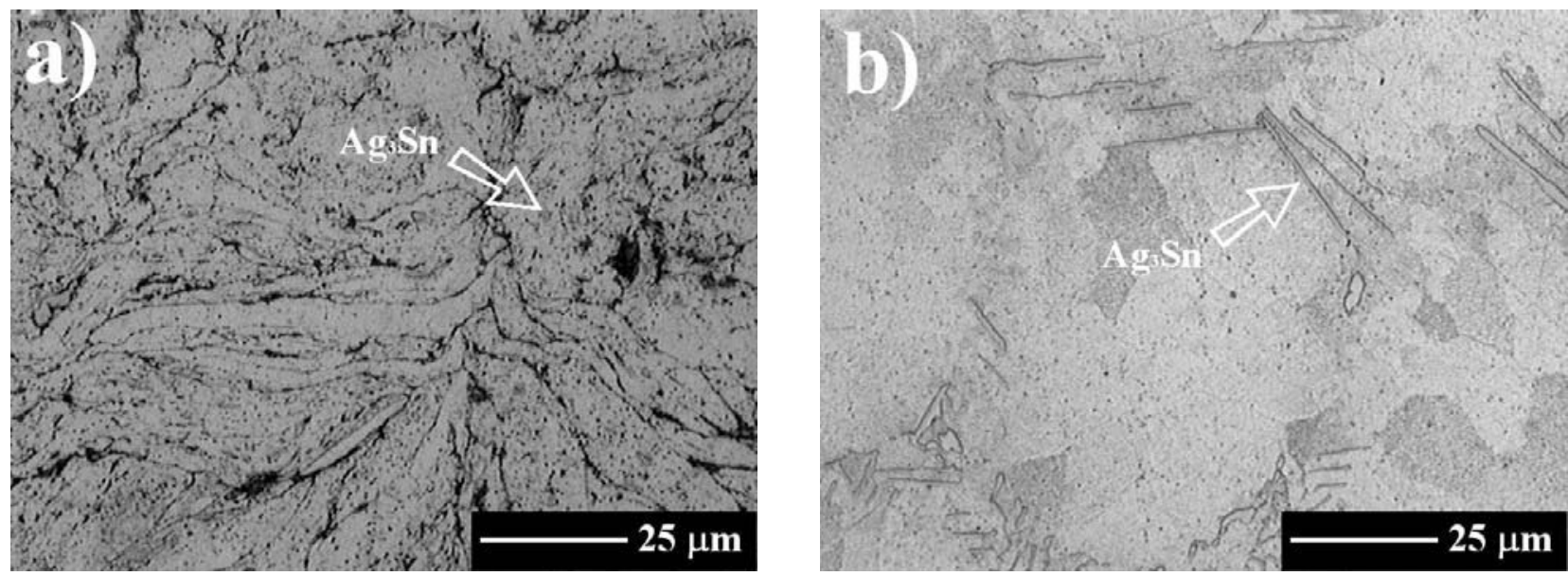

Figure 1.- Optical micrographs of Bi5-Ag3-Cu0.5-Sn solder 500x obtained by (a) MA (0.25h milling time) and cold consolidated, and (b) powders mixture processed by foundry method.
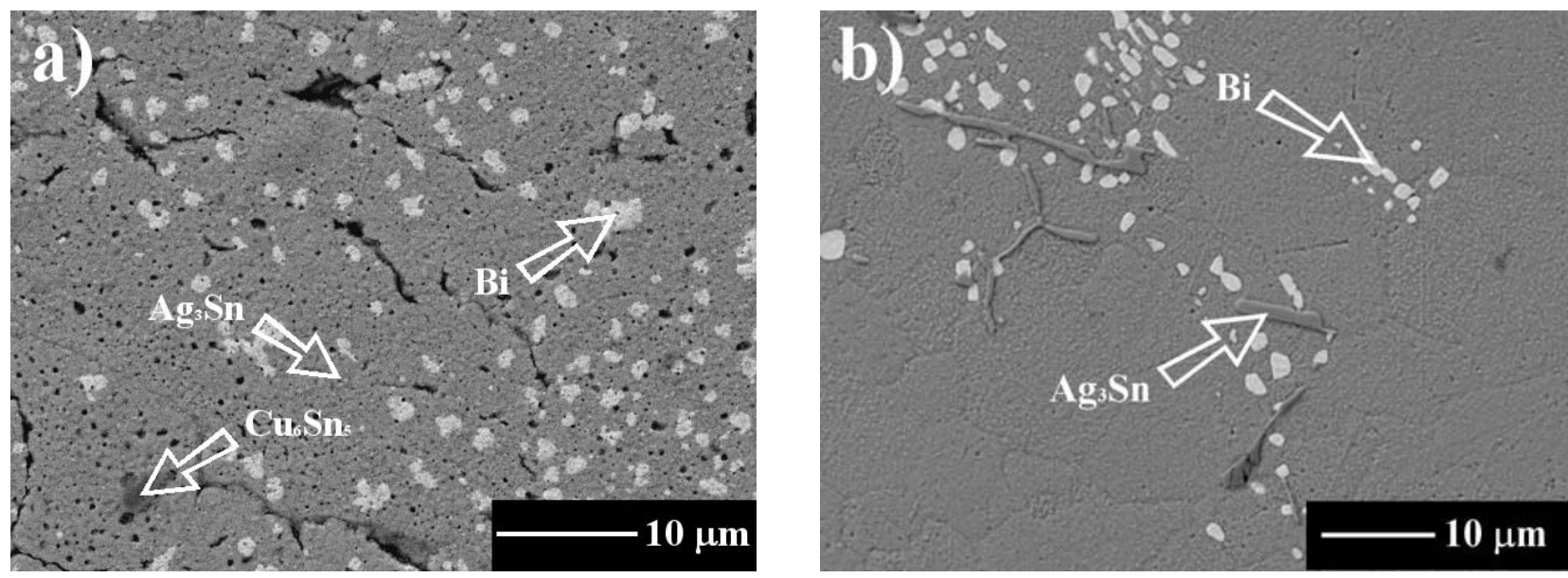

Figure 2.- SEM microstructure of Bi5-Ag3-Cu0.5-Sn solder obtained by (a) MA, and (b) foundry method. 